This item was submitted to Loughborough's Research Repository by the author.

Items in Figshare are protected by copyright, with all rights reserved, unless otherwise indicated.

\title{
Decision support systems for sustainable logistics: A review and bibliometric analysis
}

PLEASE CITE THE PUBLISHED VERSION

https://doi.org/10.1108/IMDS-09-2016-0410

PUBLISHER

(C) Emerald

VERSION

AM (Accepted Manuscript)

\section{PUBLISHER STATEMENT}

This work is made available according to the conditions of the Creative Commons Attribution-NonCommercialNoDerivatives 4.0 International (CC BY-NC-ND 4.0) licence. Full details of this licence are available at: https://creativecommons.org/licenses/by-nc-nd/4.0/

\section{LICENCE}

CC BY-NC-ND 4.0

\section{REPOSITORY RECORD}

Qaiser, Fahham, Karim Ahmed, Martin Sykora, Alok Choudhary, and Mike Simpson. 2019. "Decision Support Systems for Sustainable Logistics: A Review and Bibliometric Analysis". figshare.

https://hdl.handle.net/2134/24747. 


\title{
Decision Support Systems for Sustainable Logistics: A Review and Bibliometric Analysis
}

\author{
Fahham Hasan Qaiser ${ }^{1}$, Karim Ahmed ${ }^{2}$, Martin Sykora ${ }^{3}$, \\ Alok Choudhary ${ }^{4}$ and Mike Simpson ${ }^{5}$ \\ 1,2,3,4 School of Business and Economics, Loughborough University, Loughborough, UK \\ 5 Management School, University of Sheffield, Sheffield, UK
}

\begin{abstract}
Purpose: Decision-making in logistics is an increasingly complex task for organizations as these involve decisions at strategic, tactical and operational levels coupled with the triple bottom line (TBL) of sustainability. Decision support systems (DSS) played a vital role in arguably solving the challenges associated with decision making in sustainable logistics. This review is a systematic attempt to explore the current state of the research in the domain of DSS for logistics while considering sustainability aspects.
\end{abstract}

Design/methodology/approach: A systematic review approach using a set of relevant keywords with several exclusion criteria was adopted to identify literature related to DSS for sustainable logistics. A total of 40 papers were found from 1994 to 2015, which were then analysed along the dimensions of publishing trend, geographic distribution and collaboration, the most influential journals, affiliations and authors as well as the key themes of identified literature. The analysis was conducted by means of bibliometric and text mapping tools, namely BibExcel, gpsvisualizer, and VOSviewer.

Findings: The bibliometric analysis showed that DSS for sustainable logistics is an emerging field; however, it is still evolving but at a slower pace. Furthermore, most of the contributing affiliations belong to the United States and the United Kingdom. The text mining and keyword analysis revealed key themes of identified papers. The inherent key themes were decision models and frameworks to address sustainable logistics issues covering transport, distribution and third party logistics. The most prominent sustainable logistics issue was carbon footprinting. Social impact has been given less attention in comparison to economic and environmental aspects. The literature has adequate room for proposing more effective solutions by considering various types of MCDA (multi-criteria decision analysis) methods and DSS configurations while simultaneously considering economic, environmental and social aspects of sustainable logistics. Moreover, the field has potential to include logistics from wide application areas including freight transport through road, rail, sea, air as well as inter-modal transport, port operations, material handling and warehousing.

Originality/value: To the best of the authors' knowledge, this is the first systematic review of DSS for sustainable logistics using bibliometric and text analysis. The key themes and research gaps identified in this paper will provide a reference point that will encourage and guide interested researchers for future study, thus aiding both theoretical and practical advancements in this discipline.

Keywords: Decision Support Systems (DSS), Sustainability, Logistics, Systematic Review, Bibliometric Analysis, Text Visualization 


\section{INTRODUCTION}

Logistics is vital to the success of supply chains and inevitably linked with the overall organizational performance. The activities may involve freight transport, materials handling, storage and inventory management. Logistics has the potential of bringing tremendous impact on local as well as global trade by aiming to supply the right items at the right place and right time. In the past two decades, there has been a growing concern for environmental and social impacts of logistics besides economic aspects. In this regard, the term 'green logistics' and ‘sustainable logistics' has been used by organizations and academic researchers.

According to Chang and Qin (2009), "The green logistics refers to plan, control, management and implementation of the logistics system through the advanced logistics technology and environmental management, aiming to reduce the pollutant emission.” Zhao et al. (2009) further explained that "the meaning of green logistics is to improve resource utilization, reduce resource consumption and waste, and minimize environmental pollution when implementing logistics activities, through rational planning, optimize resource allocation and use environmental technology". Mckinnon et al. (2012) defined 'green logistics' as the study of the environmental effects of all the activities involved in logistics in both forward and reverse directions. Sbihi and Eglese (2010) suggested that "green logistics is concerned with producing and distributing goods in a sustainable way, taking account of environmental and social factors."

The most widely accepted definition of sustainable development was given by the World Commission on Environment and Development which is concerned with the fulfilment of the needs of the present without compromising the ability of future generations to meet their own needs (WCED, 1987). Elkington (1997) suggested the consideration of three closely interrelated economic, ecological (environmental) and social aspects of sustainability in a "triple-bottom line". The scope of sustainability in supply chain and logistics has also been borrowed from these concepts. However, there is still a lack of consensus among researchers over a unified definition of green and sustainable logistics, and both of these terms have been used interchangeably in the literature with a different implied scope. Moreover, the formal definition of 'sustainable logistics' is relatively scarce in literature compared to 'green logistics'. It is evident that environmental issues are extensively addressed in the literature in comparison to that of social issues, which is partially covered under green logistics. The lack of research addressing social issues in sustainable logistics gives the field a direction to develop further considering sustainability in logistics as a whole giving equal importance to economic, environmental and social aspects. In the context of this study, we are limiting our scope to those papers that have addressed economic as well as at least either the environmental or social dimension of sustainability.

Given the situation, it is now increasingly difficult for organizations to make logistical decisions at strategic, tactical and operational levels in line with the triple bottom line of sustainability. Much of the research work and initiatives were carried out to make logistics more sustainable. In this regard, and in other subject areas, Decision Support Systems (DSS) in logistics may help companies to make fast and more effective decisions.

There exist many definitions of DSS in the literature. In fact, DSS is highly context sensitive as it means different things to different people (Turban and Turban 2007). Gorry and 
Morton (1971) defined DSS as "the interactive computer-based systems, which help decision makers utilize data and models to solve unstructured problems". As the chosen subject area is comparatively new, the scope of the study is further expanded from the given DSS definition and also includes DSS frameworks and models as well as review articles that may contribute towards developing a DSS. This also involves papers addressing logistics issues alongside their focus on supply chain.

This paper is an attempt to conduct a systematic literature review of DSS for sustainable logistics, which reveals the existing state of research in this area and provides researchers and organizations with a direction to develop this field further. The remainder of this paper is organized as follows; the methodology is discussed in the next section followed by initial data analysis and statistics, bibliometric analysis, discussion section and finally the conclusion.

\section{METHODOLOGY}

According to Fink (1998), "A literature review is a systematic, explicit, and reproducible design for identifying, evaluating, and interpreting the existing body of recorded documents." Systematic literature reviews are different from conventional narrative reviews in that they are more transparent and reduce bias in literature search and summarize them objectively (Petticrew and Roberts, 2006). A three-step process for the systematic literature review is described below, which was adapted from Fahimnia et al. (2015).

1. Choosing Appropriate Search Terms: A total of 45 keywords were identified by the authors through a brainstorming process. A four level keyword assembly structure is used to gather all relevant literature where the first three levels with 37 keywords set inclusion criteria, however, the fourth level with 8 keywords sets exclusion criteria. The assembly structure is given in Table 1. The first level contains keywords belonging to decision support system, however, level two and three contain all the appropriate keywords related to logistics and sustainability respectively. The fourth level keywords are intended to filter out areas related to city logistics, municipal waste collection, pipeline and electricity distribution which are irrelevant and excluded from this study.

<<Table 1 Four Level Keywords Assembly Structure>>

2. Initial Search Results and Delimitation: The authors have chosen Scopus, which is the largest abstract and citation database of peer-reviewed research literature delivering a comprehensive overview of the world's research output in the field of science, technology, medicine, social sciences, and arts and humanities (Elsevier, 2016a). It covers over 20,000 peer-reviewed journals (Elsevier, 2016b) including those published by Elsevier, Emerald, Inderscience, Informs, Springer and Taylor and Francis. One limitation of Scopus is the limited access to the publications before 1996. However, given the emerging nature of our research area, it is unlikely to have a significant impact on our findings.

Initially, the first three levels of keywords were employed in the title, abstract and keywords search of the Scopus database. The search result returned a total of 367 articles until the end of 2015. The initial search result was further reduced gradually by using fourth 
level keywords followed by excluding health sciences papers and considering only journal articles in the English language. These limitations reduced the total number of papers to 97. Afterwards, final shortlisting of papers was carried out by the relevance of individual papers, given the context of this research, which provided the final 40 papers to be analyzed. Given the limited number of publications in this area, the authors have also considered those manuscripts which were accepted and made available online in 2015 but due for publication in 2016. The step by step exclusion criteria and the resulting number of papers are given in Table 2.

\section{$<<$ Table 2 Stepwise Delimitation $>>$}

3. Data Analysis: An inductive approach has been used for data analysis. The analysis is performed in the following sections as initial data statistics, bibliometric analysis and text visualization. BibExcel is used for the purpose of bibliometric analysis. The analysis includes author, affiliation and keyword statistics. Moreover, gpsvisualizer.com is used for mapping affiliations on their frequency. In addition, VOSviewer is used for the network analysis of title and abstract text of shortlisted papers.

\section{INITIAL DATA STATISTICS}

The Scopus database classifies the shortlisted papers into a number of subject areas. The top ten subject fields are given in Table 3. Some of the papers are mentioned in more than one field, as classified by Scopus. Furthermore, the publishing trend is shown in Fig. 1, which shows the number of papers plotted against years. The first paper appeared in 1994 by Fischer (1994). He pointed out the potential of artificial intelligence (AI) principles and techniques in a geographic information system (GIS) environment for applications including land-use planning, distribution logistics, etc. Afterwards, the field is revived in 2001 following a long gap of 7 years. Since 2001, there is an overall increasing trend of publications with some peaks and troughs. The publications have relatively increased in the past three years, however, the absolute frequency is still low. It is also observed that the 40 papers were published in 32 different journals. The top five journals that have published more than one paper and shared a total of 12 papers, representing 30 percent of all articles as shown in Table 4.

<<Table 3 The Top 10 Subject Areas $>>$

$<<$ Figure 1 Publishing Trend $>>$ 
The selected papers are classified into three categories, based on their focus on certain dimensions of sustainability, namely ENV (economic and environmental), SOC (economic and social) and SUS (economic, environmental and social). Table 5 shows the differentiation of these papers and their organization in descending order of authors based on publication year. It is revealed that 27 papers addressed both economic and environmental aspects, however, interestingly only one paper focused on economic and social dimensions. The trend of incorporating all the three dimensions of sustainability started relatively late with a total of only 12 intermittent publications since 2007.

<<Table 5 Sustainability dimensions of selected papers $>>$

\section{BIBLIOMETRIC ANALYSIS}

This section mainly presents the analysis of authors, keywords and affiliations. Identifying the key researchers and universities across the globe will help scholars, students and organizations to conduct research with relevant researchers at various universities (Fahiminia et al., 2015). In this regard, BibExcel is used for this purpose which extracts and analyses bibliographic data. The data of shortlisted papers that includes author name, affiliation, journal, paper title, abstract, publication year are exported from Scopus in RIS format which is compatible with BibExcel.

\section{Author Influence}

The data of all authors were extracted from those 40 papers and the frequency of authors was observed. It is revealed that out of 149 authors only two authors, Kengpol and Tuammee (2014, 2016) have had their papers published more than once. These authors are also found to be the only key paired authors. They belong to King Mongkut's University of Technology North Bangkok having their papers published in International Journal of Logistics Management and International Journal of Production Research in 2014 and 2016 respectively. This finding can be taken as the very beginning stage of collaboration among scholars. However, there is a need for more collaboration of scholars from different regions, universities and subject areas to enrich this field of study.

\section{Affiliation Statistics}

Likewise, based on authors' data, the affiliation data is extracted with respect to each author from RIS file using BibExcel. The city names are obtained from each affiliation where the organization is located. Using city information and its frequency, the geographical distribution of affiliations is mapped with gpsvisualizer.com; a free online utility that creates customizable maps and profiles from GPS data and addresses, and is presented in Figure 2.

The size of red spot reflects the contribution of each organization (city) associated with those 40 papers. It is apparent that greater density is found in three regions across the globe, which are; the eastern part of United States, the Western Europe and the Far East. Table 6 
presents top contributing countries along with their respective number of papers. It is apparent that the United States is the most active country in this research area, followed by European (United Kingdom and Italy), and finally the Far Eastern region. Conversely, there are only 4 top affiliations which contributed to more than one paper as shown in Table 7 . It is pertinent to note that despite the United States being the most active country in this particular field, Purdue University is interestingly the only one among the top 4 affiliations.

<<Figure 2 Geographical Location of Contributing Organizations (Using gpsvisulaizer.com)>>

<<Table 6 Top 12 Contributing Countries>>

<<Table 7 Top 4 Contributing Organizations >>

Furthermore, Table 8 shows international collaboration in the 40 papers of our study. It reveals that the top four collaborations are either with United States or United Kingdom. This could be attributed to the possibility that the authors from Far East or Europe may be pursuing their terminal research degrees from US or UK universities. However, at this moment this would require further investigation to validate this assumption.

$<<$ Table 8 International Collaboration $>>$

\section{Keyword Statistics}

The keywords belonging to each paper were extracted from the RIS file using BibExcel. Table 9 shows a list of 16 out of 70 keywords from 40 papers, which appeared at least twice. Similarly, Table 10 presents the list of most popular words appearing in the paper title. Though the frequency of keywords is limited to cover a broader scope, it is inferred from the top most words found in both tables that the current research is about helping organizational managers to solve logistical issues with the objective of reducing environmental impact. Moreover, certain decision-making approaches were also traced such as AHP, DEA and simulation. To further validate this inference and to explore this further through the text used in these studies, text mining was carried out based on the texts appearing in the titles and abstract of shortlisted papers.

<<Table 9 The Most Popular Keywords in Papers>>

<<Table 10 The Most Popular Words in Paper Titles>>

\section{TEXT NETWORK VISUALIZATION}

The texts from titles and abstracts of papers were exported in CSV (comma separated value) file format and used as input for text mining using VOSviewer software to explore the text pattern presented in Figure 3. The size of circles and text visibility are proportional to the occurrence of words. The text visualization also shows links between terms that are appearing 
together. A total of 1,462 terms were found by the software out of which 156 words were selected to be mapped that appeared at least 3 times. Though the data has certain noise and is not enough to perform rich analysis and clustering. However, the text visualization highlights the inferences made from the keywords analysis. Most of the papers are primarily concerned with proposing a model, framework, approach or decision support tool to solve logistics issues with a focus on reducing cost and environmental impact including the carbon footprint.

\section{$<<$ Figure 3 Text Visualization using VOSviewer $>>$}

However, it can be seen that social impact is given less attention in the existing body of research. Moreover, analytic hierarchy process as MCDA approach has been used for prioritizing criteria or factors for decision making. Simulation term was also witnessed in the visualization map that might have been used for both organizations and policy makers in green logistics. It is inferred that the main areas focused on sustainable logistics are transport, distribution and third party logistics. Decision making approaches addressed problems which are weakly connected to the network thus providing an opportunity to study the field in detail to explore the models and solution methods.

\section{CONCLUSIONS, LIMITATIONS AND FUTURE DIRECTIONS}

This paper presents a systematic review and bibliometric analysis of literature about decision support systems for sustainable logistics. It is pertinent to note that the state of research in this area is still in its infancy and requires swift advancement given the dynamics of business environments. We have used bibliometric and visualization tools to analyse journal paper data and have drawn the following conclusions from this study: (1) The publication trend in this area has been rising since 2013, however, the absolute frequency of these publications is still low. (2) There are only two top contributing authors in this area who are also found to be the only paired authors. (3) The only influential journal in this area is International Journal of Production Economics, which published four papers in the last two years. (4) The geographic distribution of contributing affiliations is focused at the Eastern part of North America, Western Europe and Asia. (5) The top collaborating organizations are either within the United States or the United Kingdom. (6) The keyword statistics and text visualization reveal that certain models, systems and frameworks have been proposed to solve logistical issues concerning sustainability but the research area is partially covered regarding various decision support system configurations as well as different types of problems within logistics.

Like any other research study, this paper also comes with certain limitations. Besides journal articles, conference papers could also have been included in the study and further analysis could also be performed including citation, co-citation, page rank analysis and data clustering. Moreover, content analysis may also be effective in order to identify the nature of models, issues, sustainability dimensions and technologies employed. This study is conducted on the basis of papers obtained from Scopus, which is considered to be a comprehensive database. However, there is a possibility of gathering more relevant journal articles by exploring other databases as well, such as Google Scholar, the web of science etc. The methodology used in this paper reveals only the trend at a macro level including publication trend, key affiliations, authors and journals. It does not interpret the knowledge contained in 
these papers. A more comprehensive systematic bibliometric and content analysis can be carried out to validate the results of our findings and to develop thorough understanding by including literature from other databases, including conference papers.

The findings of this paper have both academic and practical implications. The current set of findings, affirming DSS in sustainable logistics is an emerging field, will initiate accelerated development of this area including freight transport through road, rail, sea, air as well as inter-modal transport, port operations, material handling and warehousing. The geographic distribution of researchers and affiliations working in this field will help other interested researchers to identify and collaborate with them. Given the diversified nature of DSS, researchers may seek the utility of different types of DSS including knowledge-based systems, model-based systems, communication-based systems, and data-based systems or a hybrid of these. The research area has also the potential of validating the usage of artificial intelligence approaches and/or various MCDA models or a combination of them to complement the result. Moreover, there is room for researchers to realize the need of simultaneously covering economic, environmental and social aspects of sustainability in order to take into account the concerns of all stakeholders while developing a DSS. Consequently, the resulting DSS will help logistics managers in making effective decisions to make the operations profitable as well as to have a broad and long-term positive impact on the environment and society.

The implications from findings together with the limitations of this study further open new research avenues for future studies. This review is part of an ongoing project exploring this emerging field and will consider above limitations in future work.

\section{ACKNOWLEDGEMENT}

This research has been made available through the European Union EuropeAid funded Project "EU-India Research \& Innovation Partnership for Efficient and Sustainable Freight Transportation (REINVEST)”, Contract Number: R/141842. The contents of this publication are the sole responsibility of the authors of this paper and can in no way be taken to reflect the views of the European Union.

\section{REFERENCE}

Adhitya, A., Halim, I. \& Srinivasan, R. 2011, "Decision support for green supply chain operations by integrating dynamic simulation and LCA indicators: Diaper case study", Environmental Science and Technology, vol. 45, no. 23, pp. 10178-10185.

Agusdinata, D.B., Fry, D.N. \& Delaurentis, D.A. 2011, "Policies to deal with multimodal transport emissions: A system-of-systems approach", Transportation Planning and Technology, vol. 34, no. 2, pp. 109-123.

Albrecht, S., Brandstetter, P., Beck, T., Fullana-I-Palmer, P., Grönman, K., Baitz, M., Deimling, S., Sandilands, J. \& Fischer, M. 2013, "An extended life cycle analysis of packaging systems for fruit and vegetable transport in Europe", International Journal of Life Cycle Assessment, vol. 18, no. 8, pp. 1549-1567. 
Ayoub, N., Martins, R., Wang, K., Seki, H. \& Naka, Y. 2007, "Two levels decision system for efficient planning and implementation of bioenergy production", Energy Conversion and Management, vol. 48, no. 3, pp. 709-723.

Ballis, A. \& Golias, J. 2004, "Towards the improvement of a combined transport chain performance", European Journal of Operational Research, vol. 152, no. 2, pp. 420-436.

Boonsothonsatit, K., Kara, S., Ibbotson, S. \& Kayis, B. 2015, "Development of a Generic decision support system based on multi-Objective Optimisation for Green supply chain network design (GOOG)", Journal of Manufacturing Technology Management, vol. 26, no. 7, pp. 1069-1084.

Bortolini, M., Faccio, M., Ferrari, E., Gamberi, M. \& Pilati, F. 2015, "Fresh food sustainable distribution: Cost, delivery time and carbon footprint three-objective optimization", Journal of Food Engineering, .

Boutkhoum, O., Hanine, M., Tikniouine, A. \& Agouti, T. 2015, "Multi-criteria Decisional Approach of the OLAP Analysis by Fuzzy Logic: Green Logistics as a Case Study", Arabian Journal for Science and Engineering, vol. 40, no. 8, pp. 2345-2359.

Byrne, P.J. \& Ryan, P. 2010, "Simulation, a support for sustainable logistical decisionmaking in complex supply chains", International Journal of Computer Aided Engineering and Technology, vol. 2, no. 4, pp. 356-370.

Chang, Q. and Qin, R., 2009. Analysis on development path of Tianjin green logistics. International Journal of Business and Management, vol. 3, no. 9, p.96.

Dey, P.K. \& Ramcharan, E.K. 2008, "Analytic hierarchy process helps select site for limestone quarry expansion in Barbados", Journal of environmental management, vol. 88, no. 4, pp. 1384-1395.

Elkington, J.,1997, Cannibals with Forks: The Triple Bottom Line of 21th Century Business. Capstone, Oxford, pp 402.

Elsevier, 2016a, “About Scopus”, available at https://www.elsevier.com/solutions/scopus (accessed 15 October 2016)

Elsevier, 2016b, "Measuring a Journal's Impact”, available at https://www.elsevier.com/authors/journal-authors/measuring-a-journals-impact (accessed 15 October 2016)

Fahimnia, B., Tang, C., Davarzani, H., and Sarkis, J., 2015, Quantitative models for managing supply chain risks: A review. European Journal of Operational Research, vol. 247, no. 1, pp. 1-15.

Fink, A., 1998, Conducting research literature reviews. Thousand Oaks: Sage Publications.

Fischer, M.M. 1994, "From conventional to knowledge-based geographic information systems", Computers, Environment and Urban Systems, vol. 18, no. 4, pp. 233-242. 
Freire, F., Thore, S. \& Ferrão, P. 2001, "Life cycle activity analysis: Logistics and environmental policies for bottled water in Portugal", OR Spektrum, vol. 23, no. 1, pp. 159-182.

Frombo, F., Minciardi, R., Robba, M., Rosso, F. \& Sacile, R. 2009, "Planning woody biomass logistics for energy production: A strategic decision model", Biomass and Bioenergy, vol. 33, no. 3, pp. 372-383.

Gorry, G.A. and Morton, M.S., 1971, A framework for management information systems. Sloan Management Review, vol. 12, no.1, pp.55-70.

Kannegiesser, M., Günther, H.-. \& Gylfason, O. 2014, "Sustainable development of global supply chains - Part 2: Investigation of the European automotive industry", Flexible Services and Manufacturing Journal, vol. 26, no. 1-2, pp. 48-68.

Karthik, B., Raut, R.D., Kamble, S.S., Kharat, M.G. \& Kamble, S.J. 2015, "Decision support system framework for performance based evaluation and ranking system of carry and forward agents", Strategic Outsourcing, vol. 8, no. 1, pp. 23-52.

Kengpol, A. \& Tuammee, S. 2016, "The development of a decision support framework for a quantitative risk assessment in multimodal green logistics: An empirical study", International Journal of Production Research, vol. 54, no. 4, pp. 1020-1038.

Kengpol, A., Tuammee, S. \& Tuominen, M. 2014, "The development of a framework for route selection in multimodal transportation", International Journal of Logistics Management, vol. 25, no. 3, pp. 581-610.

Krikke, H. 2011, "Impact of closed-loop network configurations on carbon footprints: A case study in copiers", Resources, Conservation and Recycling, vol. 55, no. 12, pp. 11961205.

Kristianto, Y., Gunasekaran, A. \& Helo, P. 2015, "Building the "Triple R" in global manufacturing", International Journal of Production Economics, .

Lam, J.S.L. \& Lai, K.-. 2015, "Developing environmental sustainability by ANP-QFD approach: The case of shipping operations", Journal of Cleaner Production, vol. 105, pp. 275-284.

Liljestrand, K., Christopher, M. \& Andersson, D. 2015, "Using a transport portfolio framework to reduce carbon footprint", International Journal of Logistics Management, vol. 26, no. 2, pp. 296-312.

Liu, H.-. \& Wang, W.-. 2009, "An integrated fuzzy approach for provider evaluation and selection in third-party logistics", Expert Systems with Applications, vol. 36, no. 3 PART 1, pp. 4387-4398.

Macharis, C., Caris, A., Jourquin, B. \& Pekin, E. 2011, "A decision support framework for intermodal transport policy", European Transport Research Review, vol. 3, no. 4, pp. 167-178. 
Mallidis, I., Dekker, R. \& Vlachos, D. 2012, "The impact of greening on supply chain design and cost: A case for a developing region", Journal of Transport Geography, vol. 22, pp. 118-128.

Mckinnon, A., Browne, M., and Whiteing, A., 2012, Green Logistics: Improving the Environmental Sustainability of Logistics. Kogan Page Publishers, p. 392

Meade, L. \& Sarkis, J. 2002, "A conceptual model for selecting and evaluating third-party reverse logistics providers", Supply Chain Management, vol. 7, no. 5, pp. 283-295.

Mellor, W., Wright, E., Clift, R., Azapagic, A. \& Stevens, G. 2002, "A mathematical model and decision-support framework for material recovery, recycling and cascaded use", Chemical Engineering Science, vol. 57, no. 22-23, pp. 4697-4713.

Meneghetti, A., Dal Borgo, E. \& Monti, L. 2015, "Decision support optimisation models for design of sustainable automated warehouses", International Journal of Shipping and Transport Logistics, vol. 7, no. 3, pp. 266-294.

Menou, A., Benallou, A., Lahdelma, R. \& Salminen, P. 2010, "Decision support for centralizing cargo at a Moroccan airport hub using stochastic multicriteria acceptability analysis", European Journal of Operational Research, vol. 204, no. 3, pp. 621-629.

Muñoz, E., Capón-García, E., Laínez, J.M., Espuña, A. \& Puigjaner, L. 2013, "Considering environmental assessment in an ontological framework for enterprise sustainability", Journal of Cleaner Production, vol. 47, pp. 149-164.

Norlund, E.K. \& Gribkovskaia, I. 2015, "Modal split in offshore supply network under the objective of emissions minimization", Transportation Research Part D: Transport and Environment, vol. 35, pp. 160-174.

Ogawa, H., Masui, T. \& Yamada, T. 2011, "Development of a decision support system for selecting transportation mode considering CO 2 emissions", Journal of Japan Industrial Management Association, vol. 62, no. 3, pp. 117-124.

Petticrew. M., and Roberts, H., 2006, Systematic reviews in the social sciences. Blackwell Publication, Malden, MA.

Ramani, K., Ramanujan, D., Bernstein, W.Z., Zhao, F., Sutherland, J., Handwerker, C., Choi, J.-., Kim, H. \& Thurston, D. 2010, "Integrated sustainable life cycle design: A Review", Journal of Mechanical Design, Transactions Of the ASME, vol. 132, no. 9, pp. 091004109100415.

Sbihi, A. and Eglese, R.W., 2010. Combinatorial optimization and green logistics. Annals of Operations Research, 175(1), pp.159-175.

Soysal, M., Bloemhof-Ruwaard, J.M. \& Van Der Vorst, J.G.A.J. 2014, "Modelling food logistics networks with emission considerations: The case of an international beef supply chain", International Journal of Production Economics, vol. 152, pp. 57-70.

Sukumara, S., Faulkner, W., Amundson, J., Badurdeen, F. \& Seay, J. 2014, "A multidisciplinary decision support tool for evaluating multiple biorefinery conversion 
technologies and supply chain performance", Clean Technologies and Environmental Policy, vol. 16, no. 6, pp. 1027-1044.

Tang, L., Meng, Y., Wang, G., Chen, Z.-., Liu, J., Hu, G., Chen, L. \& Zhang, B. 2014, "Operations research transforms baosteel's operations", Interfaces, vol. 44, no. 1, pp. 2238.

Ting, S.L., Tse, Y.K., Ho, G.T.S., Chung, S.H. \& Pang, G. 2014, "Mining logistics data to assure the quality in a sustainable food supply chain: A case in the red wine industry", International Journal of Production Economics, vol. 152, pp. 200-209.

Tiwari, M.K., Chang, P.-. \& Choudhary, A. 2015, "Carbon-efficient production, supply chains and logistics", International Journal of Production Economics, vol. 164, pp. 193196.

Turban, E. and Turban, E., 2007. Decision support and business intelligence systems. Pearson Prentice Hall, Upper Saddle River, N.J.

Wadhwa, S., Madaan, J. \& Chan, F.T.S. 2009, "Flexible decision modeling of reverse logistics system: A value adding MCDM approach for alternative selection", Robotics and Computer-Integrated Manufacturing, vol. 25, no. 2, pp. 460-469.

WCED, 1987, World Commission on Environment and Development, Our Common Journey. Oxford University Press, Oxford, England.

Xifeng, T., Ji, Z. \& Peng, X. 2013, "A multi-objective optimization model for sustainable logistics facility location", Transportation Research Part D: Transport and Environment, vol. 22, pp. 45-48.

Zhao, P., Liu, J. and He, L., 2009, December. Study on the Development of Modern Green Logistics in China, International Conference on Innovation management, 8-9 December 2009 Wuhan China, IEEE, Los Alamitos CA, pp. 43-46.

Zhao, R., Liu, D. \& Li, Q. 2014, "Decision support system design for rail transport of hazardous materials", Proceedings of the Institution of Civil Engineers: Transport, vol. 167, no. 4, pp. 217-231. 
Table 3 Four Level Keywords Assembly Structure

Context keywords: ("Decision support" OR "DSS" OR "Expert System" OR "knowledge based system" OR "knowledge management system" OR "Model based system" OR "Data based system" OR "Data management system" OR "Communication based system" OR "Document based system" OR "Decision Management System" OR "web tool" OR "Analytics system")

AND

Logistics keywords: (logistics OR "freight transport" OR "freight transportation" OR "Inventory management" OR "material handling" OR "port handling" OR warehousing OR warehouse OR "distribution network" OR "distribution centre" OR "reverse logistics" OR "transportation mode" OR intermodal OR multimodal)

AND

Sustainability keywords: (sustainable OR sustainability OR Green OR greenhouse OR "GHG" OR Carbon OR emission OR "environmental impact" OR "Social impact" OR "socioeconomic")

AND NOT

Out of scope keywords: ( "Water distribution" OR "Water Infrastructure" OR "Pipe aging" OR "City Logistics" OR "grid" OR "solid waste" OR "waste disposal" OR "waste collection")

Table 4 Stepwise Delimitation

\begin{tabular}{|l|c|}
\hline Search Criteria & No. of Papers \\
\hline First three levels keywords search & 367 \\
\hline Exclusion of fourth level keywords & 299 \\
\hline Exclusion of health sciences subject area & 248 \\
\hline $\begin{array}{l}\text { Limitation to only journal papers (excluding conference papers, book series, } \\
\text { commercial publications etc.) }\end{array}$ & 98 \\
\hline Limitation to English language papers & 92 \\
\hline Exclusion of out of scope papers through manual screening & 40 \\
\hline
\end{tabular}

Table 3 The Top 10 Subject Areas

\begin{tabular}{|l|c|}
\hline \multicolumn{1}{|c|}{ Subject Area } & No. of Papers \\
\hline Engineering & 16 \\
\hline Business, Management and Accounting & 14 \\
\hline Decision Sciences & 13 \\
\hline Environmental Science & 12 \\
\hline Social Sciences & 11 \\
\hline Computer Science & 6 \\
\hline Economics, Econometrics and Finance & 5 \\
\hline Energy & 4 \\
\hline Mathematics & 4 \\
\hline Agricultural and Biological Sciences & 2 \\
\hline
\end{tabular}


Table 4 Top Five Journals

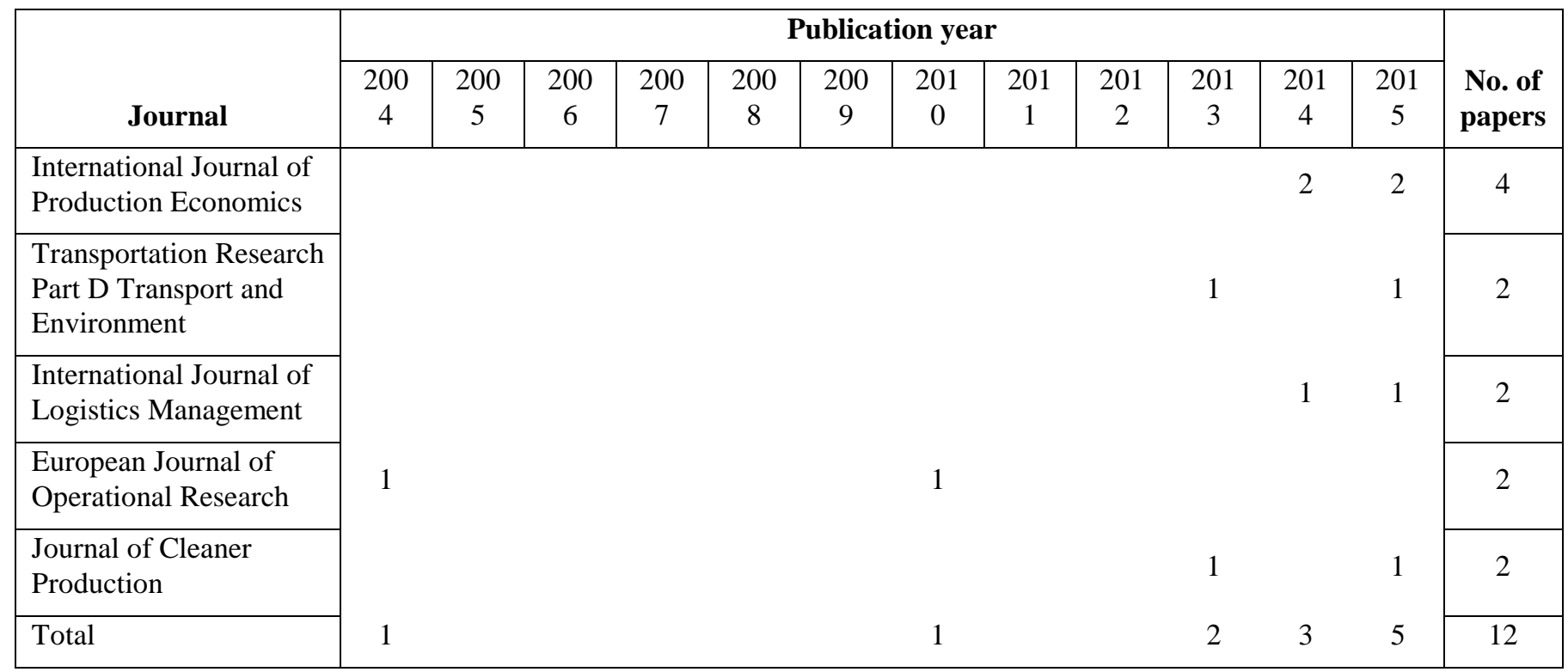

Table 5 Sustainability Dimensions of Selected Papers

\begin{tabular}{|c|c|c|c|c|c|c|c|}
\hline Authors and Years & ENV & SOC & SUS & Authors and Years & ENV & SOC & SUS \\
\hline Fischer (1994) & $\mathrm{X}$ & & & Muñoz et al. (2013) & $\mathrm{X}$ & & \\
\hline Freire et al. (2001) & $\mathrm{X}$ & & & Xifeng et al. (2013) & $\mathrm{X}$ & & \\
\hline Meade \& Sarkis (2002) & $\mathrm{X}$ & & & Kannegiesser et al. (2014) & $\mathrm{X}$ & & \\
\hline Mellor (2002) & $\mathrm{X}$ & & & Kengpol et al. (2014) & $\mathrm{X}$ & & \\
\hline Ballis \& Golias (2004) & $\mathrm{X}$ & & & Soysal et al. (2014) & $\mathrm{X}$ & & \\
\hline Ayoub et al. (2007) & & & $\mathrm{X}$ & Sukumara et al. (2014) & & & $\mathrm{X}$ \\
\hline Dey \& Ramcharan (2008) & & & $\mathrm{X}$ & Tang et al. (2014) & $\mathrm{X}$ & & \\
\hline Frombo et al. (2009) & $\mathrm{X}$ & & & Ting et al. (2014) & $\mathrm{X}$ & & \\
\hline Liu \& Wang (2009) & & $\mathrm{X}$ & & Zhao et al. (2014) & & & $\mathrm{X}$ \\
\hline Wadhwa et al. (2009) & $\mathrm{X}$ & & & Boutkhoum et al. (2015) & & & $\mathrm{X}$ \\
\hline Byrne \& Ryan (2010) & $\mathrm{X}$ & & & Boonsothonsatit et al. (2015) & $\mathrm{X}$ & & \\
\hline Menou et al. (2010) & & & $\mathrm{X}$ & Bortolini et al. (2015) & $\mathrm{X}$ & & \\
\hline Ramani et al. (2010) & $\mathrm{X}$ & & & Karthik et al.(2015) & & & $\mathrm{X}$ \\
\hline Agusdinata et al. (2011) & $\mathrm{X}$ & & & Kengpol \& Tuammee (2016) & $\mathrm{X}$ & & \\
\hline Adhitya et al. (2011) & $\mathrm{X}$ & & & Kristianto et al. (2015) & & & $\mathrm{X}$ \\
\hline Krikke (2011) & $\mathrm{X}$ & & & Lam \& Lai (2015) & & & $\mathrm{X}$ \\
\hline Macharis et al. (2011) & & & $\mathrm{X}$ & Liljestrand et al. (2015) & $\mathrm{X}$ & & \\
\hline Ogawa et al. (2011) & $\mathrm{X}$ & & & Meneghetti et al. (2015) & $\mathrm{X}$ & & \\
\hline Mallidis et al. (2012) & $\mathrm{X}$ & & & Norlund \& Gribkovskaia (2015) & $\mathrm{X}$ & & \\
\hline Albrecht et al. (2013) & & & $\mathrm{X}$ & Tiwari et al. (2015) & & & $\mathrm{X}$ \\
\hline
\end{tabular}


Table 6 Top 12 Contributing Countries

\begin{tabular}{|l|c|l|c|}
\hline Country & No. of Papers & Country & No. of Papers \\
\hline United States & 18 & Hong Kong & 3 \\
\hline United Kingdom & 9 & Thailand & 3 \\
\hline Italy & 6 & Singapore & 3 \\
\hline Finland & 5 & Netherlands & 3 \\
\hline Germany & 4 & India & 3 \\
\hline China & 4 & Belgium & 3 \\
\hline
\end{tabular}

Table 7 Top 4 Contributing Organizations

\begin{tabular}{|l|l|c|}
\hline Organization & Location & No. of papers \\
\hline Purdue University & United States & 3 \\
\hline Loughborough University & United Kingdom & 2 \\
\hline Lappeenrannan Teknillinen Yliopisto & Finland & 2 \\
\hline King Mongkut's University of Technology & Thailand & 2 \\
\hline
\end{tabular}

Table 8 International Collaboration

\begin{tabular}{|l|l|c|}
\hline Country 1 & Country 2 & No. of papers \\
\hline China & United States & 2 \\
\hline Spain & United States & 2 \\
\hline Switzerland & United States & 2 \\
\hline China & United Kingdom & 2 \\
\hline
\end{tabular}

Table 9 The Most Popular Keywords in Papers

\begin{tabular}{|l|c|l|c|}
\hline Words & Frequency & Words & Frequency \\
\hline Decision Support Systems & 5 & Simulation & 2 \\
\hline Carbon Footprint & 4 & Biomass & 2 \\
\hline Analytic Hierarchy Process (AHP) & 3 & Quantitative Risk Assessment (QRA) & 2 \\
\hline Supply Chain & 3 & Decision Support & 2 \\
\hline Sustainability & 3 & Environmental & 2 \\
\hline Decision Support System & 3 & Reverse Logistics & 2 \\
\hline Supply Chain Management & 3 & Carbon Dioxide Emissions & 2 \\
\hline Sustainable Logistics & 2 & Data Envelopment Analysis (DEA) & 2 \\
\hline
\end{tabular}


Table 10 The Most Popular Words in Paper Titles

\begin{tabular}{|l|c|l|c|}
\hline Words & Frequency & Words & Frequency \\
\hline Decision & 13 & Approach & 6 \\
\hline Logistics & 12 & Transport & 6 \\
\hline Support & 11 & Design & 5 \\
\hline Supply & 11 & Development & 5 \\
\hline System & 8 & Study & 4 \\
\hline Chain & 8 & Model & 4 \\
\hline Sustainable & 7 & Operations & 4 \\
\hline Case & 7 & Analysis & 4 \\
\hline Framework & 7 & Green & 4 \\
\hline
\end{tabular}

12

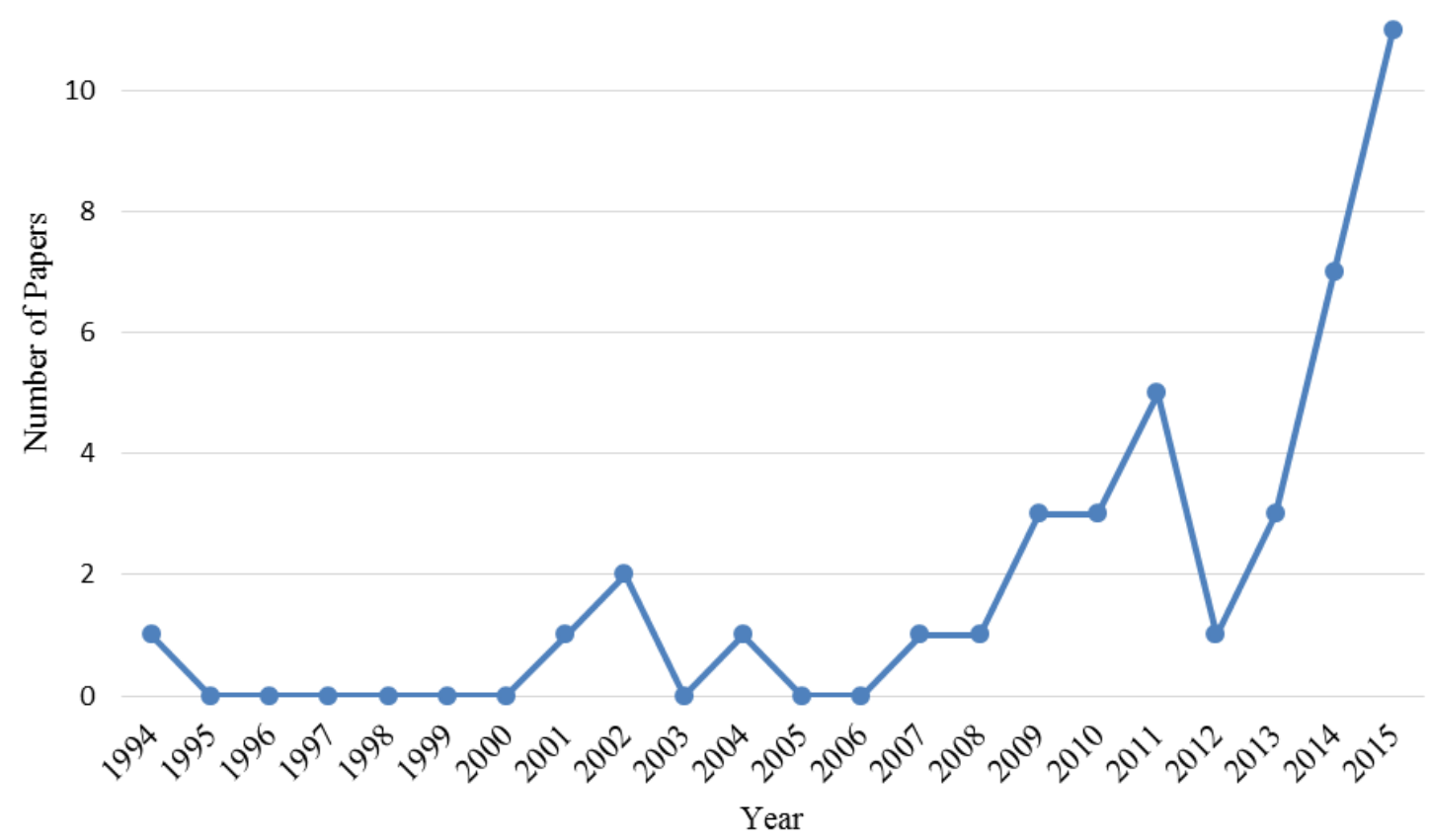

Figure 1 Publishing Trend 


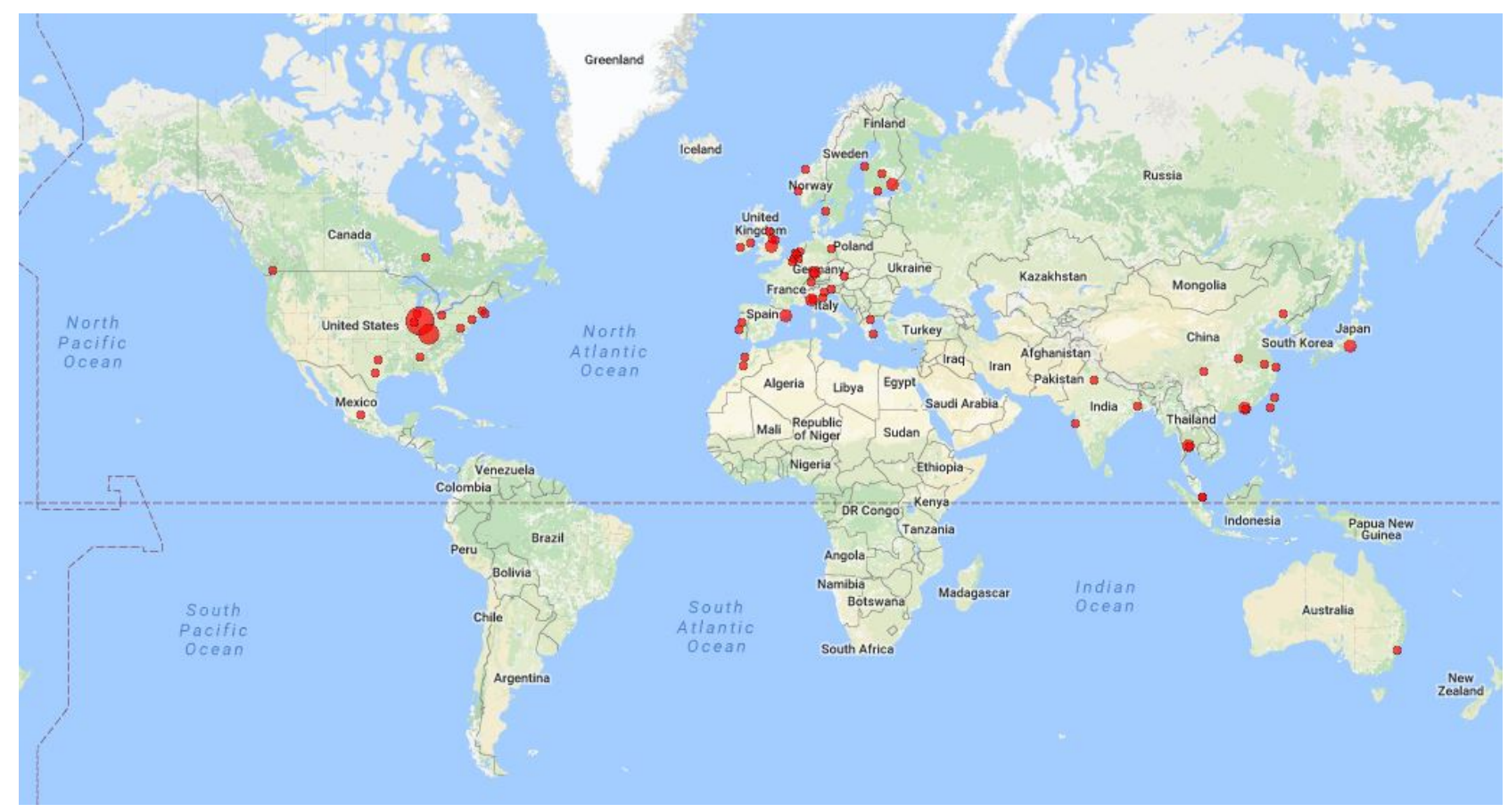

Figure 2 Geographical Location of Contributing Organizations (Using gpsvisulaizer.com)

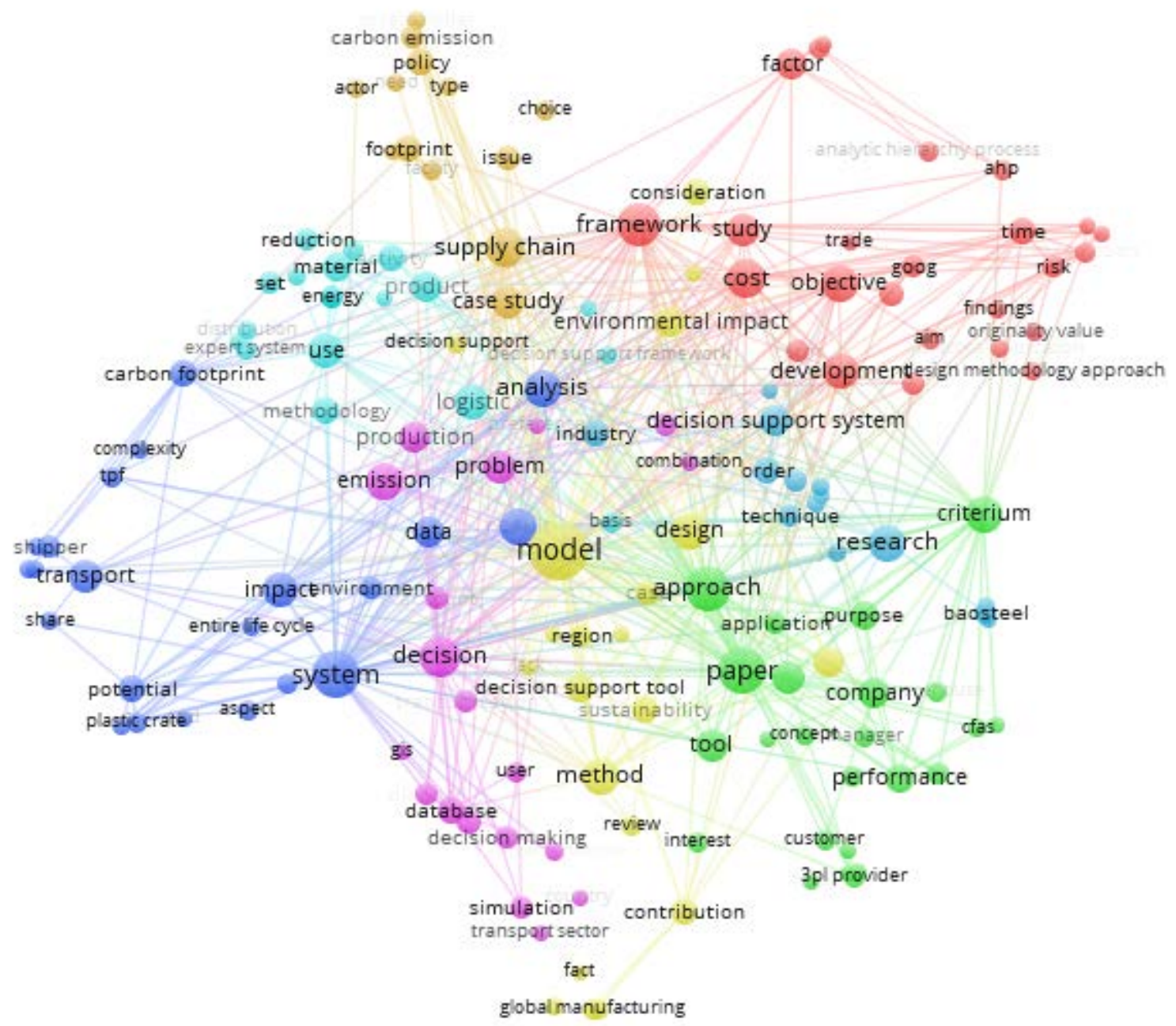

Figure 4 Text Visualization using VOSviewer 